Article

\title{
Difference in Executive Functions Development Level between Two Groups: Preschool Children Who Took Extra Music Classes in Art Schools and Children Who Took Only General Music and Dance Classes Offered by Preschools
}

\author{
Larisa Bayanova $^{1, *}$, Elena Chichinina ${ }^{2} \mathbb{D}$, Aleksander Veraksa ${ }^{1}$, Olga Almazova ${ }^{3}$ and Alexandra Dolgikh ${ }^{1}$ \\ 1 Laboratory of Childhood Psychology and Digital Socialization, Psychological Institute, Russian Academy of \\ Education, Moscow 125009, Russia; veraksa@yandex.ru (A.V.); ag.dolgikh@mail.ru (A.D.) \\ 2 Department of Educational Psychology and Pedagogy, Faculty of Psychology, Lomonosov Moscow State \\ University, Moscow 125009, Russia; alchichini@gmail.com \\ 3 Department of Developmental Psychology, Faculty of Psychology, Lomonosov Moscow State University, \\ Moscow 125009, Russia; almaz.arg@gmail.com \\ * Correspondence: balan7@yandex.ru
}

check for

updates

Citation: Bayanova, L.; Chichinina,

E.; Veraksa, A.; Almazova, O.;

Dolgikh, A. Difference in Executive

Functions Development Level

between Two Groups: Preschool

Children Who Took Extra Music

Classes in Art Schools and Children

Who Took Only General Music and

Dance Classes Offered by Preschools.

Educ. Sci. 2022, 12, 119. https://

doi.org/10.3390/educsci12020119

Received: 22 December 2021

Accepted: 7 February 2022

Published: 10 February 2022

Publisher's Note: MDPI stays neutral with regard to jurisdictional claims in published maps and institutional affiliations.

Copyright: (C) 2022 by the authors. Licensee MDPI, Basel, Switzerland. This article is an open access article distributed under the terms and conditions of the Creative Commons Attribution (CC BY) license (https:// creativecommons.org/licenses/by/ $4.0 /)$.

\begin{abstract}
Previous studies have shown that there is a positive correlation between attending music classes regularly and the development of executive functions. This paper discusses the results of a pilot study dedicated to determining the difference in the level of development of the components of executive functions (inhibitory control, cognitive flexibility, and working memory), between 5-6year-old children taking extra music classes, and children who participated only in general music and dance education in kindergarten. A total of 94 senior preschoolers from Moscow kindergartens took part in the study. Children were selected into an "extra music lessons" group and a "general preschool music and dance lessons" group based on the results of a questionnaire on supplementary education, which was filled in by parents prior to the research starting. The respondents from the "extra music and dance lessons" group attended music classes in art schools at least two times a week, both in individual and group formats. The current study revealed that children attending regular extra music classes had a higher level of inhibitory control, audio-verbal working memory, cognitive flexibility, and general coordination of the development of all executive functions. The obtained results support the value of regular extra music classes at preschool age. Moreover, this pilot study allows us to articulate the recommendations for further research in this direction.
\end{abstract}

Keywords: executive functions; inhibitory control; cognitive flexibility; working memory; preschool age; children; music; music classes

\section{Introduction}

Active development of executive functions (hereinafter, EF) takes place at preschool and junior school age [1,2]. EFs are cognitive processes allowing purposeful control of one's behavior. A. Miyake's model distinguishes three separate, yet interrelated, components of EFs: working memory (visual and audio-verbal), cognitive flexibility (attention focusing and/or attention switching under conditions of changing targets), and inhibitory control (an ability to inhibit a dominant response) [3]. EFs act as prerequisites for successful social adaptation and further achievements in school [4-8]. According to Diamond \& Lee [9], if one wants certain classes to contribute to EF development, they should be interesting for the children, and bring them positive emotions [10]. In addition, it is important that during the classes, not only is the learning itself prioritized, but so are social and emotional development, and the enhancement of the feeling of belonging to a social group. It is also crucial to increase the complexity of classes for the purposes of EF development. Music 
classes for preschoolers could supposedly meet the criteria mentioned above; thus, they are potentially applicable for EF training.

Throughout the last decades, the role of music classes in respect to EF development in preschoolers has been a point of focus in the field [11]. Preschool age is a key period during which EFs develop [12]; therefore, it is important to study the ways in which their development can be stimulated [13]. The novelty of the current study lies in the fact that, at the moment, there are no Russian research works on this matter. In addition, the existing data on the interrelation of music classes and the development of different EF components are of an ambiguous nature [14]. There are even some works demonstrating the absence of such a connection [15], and they increase the significance of thorough investigation of this problem.

The study of the influence of music over emotional and personal development goes back almost one hundred years. However, only in the last decades did the effect of music on arbitrariness development, and EFs in particular, came into the spotlight.

An entire range of research works confirm a positive connection between music classes taken at preschool age and the development of EFs, emotional self-regulation, and other parameters of the development of arbitrariness. For example, the study by Winsler A. et al [16] revealed that 3-4-year-old children who took music classes demonstrated higher levels of self-regulation, and produced more efficient strategies when performing corresponding diagnostic tasks, than the control group respondents. Williams et al. [11] discovered that in the perspective of EF development, even the domestic musical environment was of importance. That work revealed a positive correlation between the frequency of parent-child musical activities at the age of 2-3 years and the measures of self-regulation and emotional self-regulation at the age of $4-5$.

The majority of the research using the three-component EF model by A. Miyake indicates that music classes are related to the development of such parameter as inhibitory control [13,17-23]. Moreover, even time-limited music classes already contribute to the development of this EF component. For instance, 4-6-year-old children who took up music, by means of special software, improved their performance on the inhibition task (go/no-go) after 20 days of training, while no significant changes were observed in the group taking up graphic arts with the same software [17].

The paper by M.C. Fasano et al. [22] describes that a three-month course of playing musical instruments in an orchestra contributed to the improvement of inhibitory control in 8-10-year-old children (compared to their peers who did not take any of such classes). In another study, where two groups of 6-7-year-olds attended music classes throughout 2.5 years, one group took art classes, and another one took no such classes [19]. At the end of that period, respondents from music groups performed much better in the inhibition tests, the Tower of London test, and the verbal part of the Wechsler Scales (compared to other groups) [19].

The research work that involved children who took up music for 5 years revealed that they were much better in delayed reward tasks and flanking problems than children who did not take up music [21]. This study also implemented MRT technologies, which allowed registration of the following: "musical children" demonstrated higher brain activity in the right inferior frontal gyrus associated with the control of impulsive decisions, while performing a color-word Stroop task.

Bugos \& DeMarie [13] randomly assigned 34 4-5-year-old children either to musical training (experimental group) or Lego training (control group). Before the training, the children completed a pre-test, then took two 45 min classes per week for 6 weeks. The results showed that verbal-based aspects of inhibition (the day/night Stroop task) improved for both groups. Whereas visual-based aspects of inhibition (the matching familiar figures test), involving motor control, showed a significant change for the music group but not for the Lego group.

Bowmer et al. [12] investigated the effect of weekly musicianship training on the executive function abilities of 363 - to 4-year-old children using a two-phase experimental 
design. In Phase 1, Group A took part in eight weekly music classes, while Groups B and C, combined, engaged in nursery free play. The results of the first phase showed Group A to have improved on measures relating to planning and inhibition skills (the Tower of London task and the peg tapping task). During the second phase, Group A continued to take music classes while Group B took music classes for the first time and Group C participated in art classes. A repeated measures ANOVA showed a nearing-significant difference in the peg tapping task between the three groups during Phase 2.

The post-test results of another study with an experimental design showed that the children who took music training had a significantly improved automatic response inhibition (NEPSY-II) [23]. The study involved 160 5-year-old children divided into two groups; one group took music classes, and the other developed physical abilities and motor functions by guided and free play. Children in the both groups took part in 19 weekly 40-min sessions.

Research works that confirm the influence of music classes on working memory also indicate that both audio-verbal and visual working memory develop better in children who take music classes, compared to the ones who do not $[18,20]$. However, a number of papers emphasized that music classes only affected audio-verbal working memory $[19,24]$. For example, the study where the socioeconomic level of participating families was controlled, together with children's IQ level, revealed that 7-year-olds who played musical instruments once a week, for 18 months, developed significant improvement in audial memory, in contrast to children who did not take music classes. However, no differences in visual memory were registered [24]. The majority of research works on this matter do not confirm any relationship between music classes in preschool age and cognitive flexibility development; yet, we found a few papers that discuss the existence of such connection [18,25].

Most of the reviewed studies show that music training can influence the development of EFs in preschool children. However, these studies focus on inhibitory control [23] and, in our opinion, there is a lack information about the influence of music training on other components of EFs (cognitive flexibility and working memory), and also coordination of the development of all EF components. This topic is not covered in Russian scientific literature, although the Russian preschool music education system may have its own unique features, and it would be interesting to analyze these features in terms of their influence on EF development.

Our study was a pilot and primarily focused on identifying possible questions and difficulties while designing future studies of this topic. Due to the pilot nature of this work, we used a correlational research design: we selected those children who were already taking extra music classes in art schools and compared how developed their EFs were to other children who were attending general music classes in kindergartens. This pilot nature is also the reason why the sample group was not big and music classes were of different types.

The current study aimed to investigate the difference in the level of the development of EF components in 5-6-year-old children who participated extra music (and dance) education lessons in arts school, and children who participated only in general music and dance education offered by pre-primary education. Based on the reviewed literature we assumed that the former would demonstrate a higher level of inhibitory control and audio-verbal working memory.

\section{Materials and Methods}

\subsection{Sample and Diagnostic Procedure}

94 senior preschoolers participated in the research. Their ages varied from 56 to 73 months at the research baseline $(\mathrm{M}=65 ; \mathrm{SD}=4)$. For each respondent taking extra music classes, a preschooler of the same age and gender was selected from the "group of general preschool music and dance lessons". In the end, there were 47 children in each group-19 male and 28 female participants. All of the children resided in Moscow during the study. 
The division of subjects between the two groups- "extra music lessons" and "general preschool music and dance lessons"-was performed based on the results of a questionnaire on supplementary education, filled in by parents prior to the research starting. All parents gave their informed consent for their children to participate in the study. The information collected in the study was anonymous. The study and consent procedures were approved by the Ethics Committee of the Faculty of Psychology at Lomonosov Moscow State University (approval no: 2021/81).

Children from the "extra music lessons" group took music classes at least two times a week, both in individual and group formats. The types of the classes varied depending on the art school, but mostly, these were not instrument-specific classes; rather, they were general comprehensive music training. Such classes included vocal and choir singing, musical and rhythmical activities, moving along with the music, introduction to the rudiments of music, and group musical practice. All children from the "extra music lessons" group had been taking classes for at least 1 month, and the vast majority for half a year. Some of the children also attended dancing classes, which were similar to music classes (with the use of music itself, and the high importance of rhythm the coordination of movements with the tune). The "general preschool music and dance lessons" group received no extra dancing or music education except standard music and dance classes provided by the kindergartens which participated in the study. All such kindergartens had weekly basic music and dance training for all children.

EF diagnostic procedure followed this protocol: children from the "general preschool music and dance lessons" group were tested in kindergarten on working days, and those who attended extra music classes were tested in their corresponding art schools (either on the days when the classes took place or when their parents brought them on weekends). Due to the limited amount of time during which 5-6-year-old children can focus on completing test assignments, the testing was performed during two sessions. This way, each child participated in two sessions of 20-25 min long each. The tasks were given to the children of both groups in the same order.

\subsection{Methods}

The test battery consisted of tasks which assessed three main components of children's EFs: working memory, cognitive flexibility, and inhibitory control. The majority of techniques applied in the study were Russian versions of subtests from the neuropsychological complex NEPSY-II [26]. According to the authors of this complex, it is based on the cultural-historical theory largely represented in the works of A.R. Luria [27].

Verbal working memory. We used the NEPSY-II subtest "Sentence Repetition" for children aged 3 to 6 years. The stimuli included 17 sentences of increasing length and complexity. The child was read one sentence and asked to repeat it immediately after it was presented. Each correct repetition of the sentence scored 2 points. If the child made one or two mistakes, the response scored 1. If there were many more mistakes at the attempt, the sentence scored 0 points. The procedure was stopped when the child received 0 points three times consecutively. Accuracy scores were calculated ( $\max =34$ points).

Visual working memory. We used the "Memory for Designs" subtest of NEPSY-II. It is designed to assess spatial memory for novel visual material for children aged 3 to 16 years. The stimuli included four pictures of a grid with four to eight colored designs on it (for 5-6-year-old children, we used subtests from 2 to 5, with 4, 6, 6, and lastly, 8 designs on the page). The child was shown a picture for $10 \mathrm{~s}$, and then it was removed from view. The child selected the designs from a set of cards, and placed the cards in a grid in the same location as previously shown. For each trial, points were scored separately by these four parameters: (1) the content score assessed the child's ability to recall which designs were shown for each trial; (2) the spatial score assessed the child's ability to recall where a design was shown for the trial; (3) the bonus score reflected the child's ability to recall which designs were in which locations for that trial; (4) the total score for each trial was the 
sum of the content, spatial and bonus scores. The final results of this subtest equaled to the sum of all of the scores ( $\max =120$ points).

Cognitive Inhibition. We used the "Inhibition" subtest of NEPSY-II, which is designed to assess multiple aspects of executive functioning including inhibitory control, cognitive flexibility, and self-monitoring. The subtest consists of two blocks: a series of white and black figures (circles and squares) and a series of arrows pointing in different directions (up and down). Two tasks were carried out with each series of pictures: the task of naming figures (in this case a child simply had to name the figures that s/he saw as quickly as possible), and the task for inhibition (in this case a child was supposed to say the opposite of what they saw; for example, if s/he saw a square, s/he had to say "circle", etc.). Three indicators in each task were registered: (1) the number of self-corrected errors which took place when the child produced an incorrected response or skipped a shape, but then corrected the incorrect or skipped response; (2) the number of uncorrected errors which occurred when the child did not correct his/her mistakes; (3) the completion time. Then these three indicators were translated into a combined score using the tables from the NEPSY-II manual (from 1 to 20 points).

Physical inhibition. The "Statue" subtest of NEPSY-II is aimed at inhibition and selfcontrol of bodily movements. In this task, a child needed to stand motionless in a certain position for $75 \mathrm{~s}$, without being distracted by external sound stimuli. For each 5 -s interval, the types of mistakes were registered (i.e., movements such as the opening of the eyes or vocalizations), and the child received $0-2$ points for the successful completion of the task (maximum 30 points). Two points were assigned if he/she did not make any mistakes during the $5 \mathrm{~s}$ interval, 1 point for one type of mistake, and 0 points for 2 or more types of mistake.

Cognitive flexibility. We used the Dimensional Change Card Sort (DCCS) [28]. Children were required to sort a series of bivalent test cards (with pictures of red rabbits and blue boats); first, they sorted 6 cards according to one dimension (color) and then 6 cards according to another (shape). On the third try, the child had to sort 12 cards according to a more complicated rule with an additional factor (if the card had a frame, then he/she was to sort it by color, and if there was no frame, then he/she had to sort it by form). For each correctly sorted card, a child was awarded one point, and at the end of the task, the number of points for each try was added (max 24 points).

\section{Results}

Table 1 contains the averages and standard deviations of the results of EF diagnostics in children who were taking extra music classes and those who were not, and the comparison of the measures. We used a Mann-Whitney $U$ test for independent samples, and a nonparametric test needed for consistency (some parameters were not distributed normally) - the Kolmogorov-Smirnov test.

Thus, the preschoolers who took extra music classes performed better compared to the preschoolers who took only general music and dance classes in kindergarten, in the following techniques:

(1) "Sentence Repetition";

(2) "Dimensional Change Card Sort" (frame-trial and total score); and

(3) "Inhibition" (combined score for "Naming" and "Inhibition" parameters).

These results showed that children who took regular extra music classes had a higher level of audio-verbal working memory, cognitive flexibility and inhibitory control.

Figure 1 represents correlation Pleiades for different components of preschoolers' EFs from the "general preschool music and dance lessons" group (a), and "extra music lessons" group (b) (Spearman correlation coefficient, significant connections marked with lines; $p<0.05)$. "Extra musical" preschoolers demonstrated more connections between the measures of EF components than their peers, who took up only general music and dance lessons. By using correlation Pleiades, our work revealed that the children who took regular extra music classes demonstrated better coordination of the development of 
different EF components than children who took only general music and dance classes in preschools.

Table 1. Averages and standard deviations in the measures of the level of executive function development in children taking extra music classes, and children taking only general music and dance classes.

\begin{tabular}{|c|c|c|c|c|c|c|}
\hline \multirow[t]{2}{*}{ Executive Function Components } & \multicolumn{2}{|c|}{$\begin{array}{l}\text { "General Preschool } \\
\text { Music and Dance } \\
\text { Lessons Group" }\end{array}$} & \multicolumn{2}{|c|}{$\begin{array}{c}\text { "Extra Music } \\
\text { Lessons Group" }\end{array}$} & \multicolumn{2}{|c|}{ Differences } \\
\hline & $\mathbf{M}$ & SD & $\mathbf{M}$ & SD & $\mathbf{U}$ & $p$-Level \\
\hline $\begin{array}{c}\text { Audio-verbal working memory (“Sentence Repetition”, total } \\
\text { score) }\end{array}$ & 18.04 & 4.090 & 19.89 & 3.523 & 745.500 & 0.021 \\
\hline Visual working memory ("Memory for Designs", total score) & 68.18 & 17.846 & 75.48 & 21.570 & 822.000 & 0.091 \\
\hline Cognitive flexibility ("Dimensional Change Card Sort", frame) & 7.55 & 2.376 & 8.70 & 2.367 & 805.000 & 0.022 \\
\hline $\begin{array}{c}\text { Cognitive flexibility (“Dimensional Change Card Sort", total } \\
\text { score) }\end{array}$ & 19.34 & 2.452 & 20.51 & 2.475 & 826.500 & 0.033 \\
\hline Inhibitory control (“Inhibition”, Naming, combined score) & 9.60 & 3.208 & 11.96 & 3.014 & 663.000 & 0.001 \\
\hline Inhibitory control ("Inhibition", Inhibition, combined score) & 9.89 & 3.298 & 12.21 & 2.545 & 605.000 & $<0.001$ \\
\hline Behavioral inhibitory control ("Statue", total score) & 23.89 & 5.858 & 26.24 & 3.354 & 856.000 & 0.082 \\
\hline
\end{tabular}

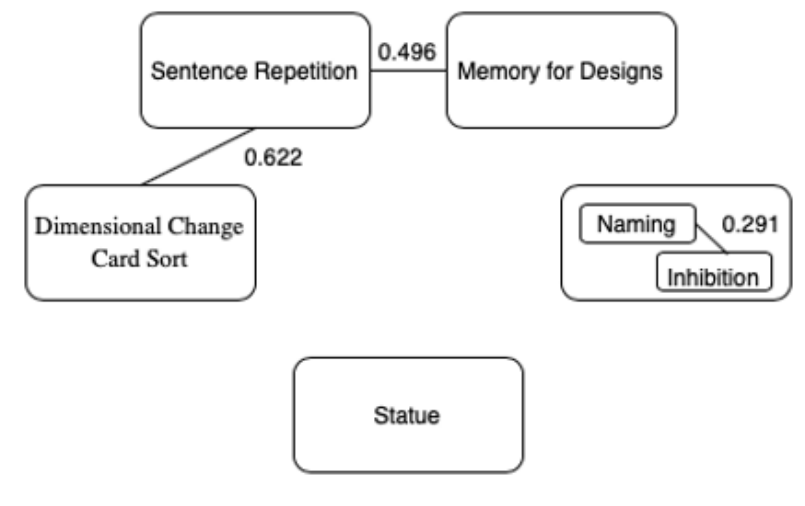

(a)
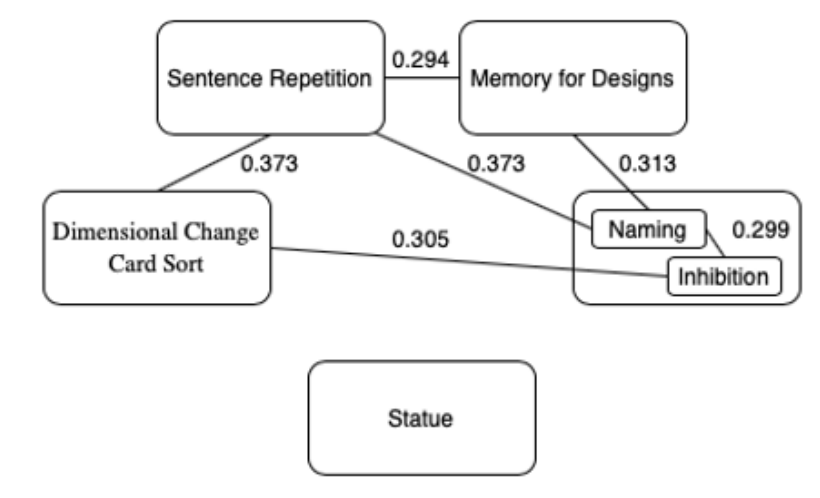

(b)

Figure 1. Correlation Pleiades of measures of EF components in preschoolers from "general preschool music and dance lessons" group (a) and "extra music lessons" group (b).

\section{Discussion}

This study aimed to compare the development of three EF components in 5-6-year-old children who took extra music classes, and their peers who took only general music and dance classes offered by preschools. We proceeded on the assumption that preschoolers from the "extra music group" have a higher level of inhibitory control and audio-verbal working memory. This hypothesis was confirmed, but along with that, it was revealed that the "extra music" group had better-developed cognitive flexibility and general coordination of the development of all of the components of EF.

\subsection{Inhibitory Control}

This research work revealed that children who took regular extra music classes had a higher level of inhibitory control. This outcome is consistent with the majority of the results of correlation studies and interventional studies that demonstrated that music classes, indeed, improved children's inhibitory control [13,17-20,23,29]. With this being said, there are a few experimental works that did not register any influence of music classes on this parameter $[30,31]$. The absence of such an effect appearing in these research works might be explained by the insufficient continuance of music classes [29]. In addition, these studies included children with a very wide age range, and they were older than senior preschoolers 
(6-9 years old in the D' Souza et al. [29] study; 6-14 years old in the work by Alema' $\mathrm{n}$ et al. [30]). Therefore, one could assume that the average age of the participants was already beyond that sensitive age for the intensive development of inhibitory control [29]. This is why short-term music classes (3 months) did not really affect the level of this EF component. In the current study, the level of behavioral inhibitory control assessed with the "Statue" tool also came out higher in the "musical" group. However, group differences did not reach a statistically significant level. One could suggest that children aged 5-6 years old are not sensitive to the intensive development of inhibitory control, and in order to achieve more significant progress, a longer period of music education is needed. Meanwhile, in our study, many of the participants only attended art schools for 6 months or so. It is worth noting that in the majority of these schools, music classes are provided in a play format; they combined various activities that required inhibitory control to a different extent. However, from the perspective of some of the authors, it is the playing of music that requires the biggest extent of inhibitory control compared to listening to it, discussing it, or even to musical games [29]. The fact is, when a child plays music, he/she actually has to suppress his/her impulsive behavior in order to be able to play and instrument, or sing only when his/her turn comes. At the same time, it is vital to inhibit automatized reactions when changing the key or the pace. During ensemble performances or choir singing, selective attention is required to be able to focus on other performers' sound. However, on the other hand, a musical play environment also promotes inhibitory control development, because every game has rules that require children to possess this very skill to follow them [32]. In any case, it is crucial to emphasize that music classes of any kind support the development of inhibitory control in 5-6-year-old children, as they have to follow the instructions given in the class, keep up with the rhythm (even if it is a simple game or a dance), and match the mood and the volume of the music.

\subsection{Working Memory}

Our study demonstrated the connection between extra music classes and the development of audio-verbal working memory, but not with visual memory. This result is consistent with other research works $[19,24]$. However, there are data confirming the effect of music classes on this EF component [18,29]. In the experimental work of Frischen, Schwarzer, \& Deg' e [29], children learned to play musical instruments only, and therefore, had to read the note sheet simultaneously while playing. It would be a rightful assumption that this type of activity supported visual working memory development, if compared to mixed music classes where children also sang, listened to music, danced, played rhythmical games, etc. It is important that, in that case [29], dynamic visual working memory was assessed. Therefore, the improvement of the scores, in fact, confirmed that playing musical instruments developed not the storage but the processing of visual information. In our study, the "extra music" group also demonstrated a higher level of visual working memory than the "general music and dance" group, but these differences were not statistically significant. This can probably be explained by the fact that only some of the children from the first group actually learned how to play and study the rudiments of music, while others just took mixed music classes; the latter just played rhythmical music games, played music in a group but without reading the notes, listened and danced to the music, and so on. In addition, there is a whole range of research works confirming that the most intensive development of visual working memory takes place at a later age [33]. Consequently, preschoolers would need continuous classes to achieve noticeable improvement of their visual working memory. An interesting aspect of our work is the use of the "Sentence Repetition" tool for the assessment of audio-verbal working memory. Some other researchers used stimuli consisting of words [34], whereas we opted for complete sentences. It is valid to claim that the latter are closer to music than words alone, because when pronouncing sentences, we use intoning, a certain rhythm, and accents (the same as in music). Thus, music classes improve audio-verbal working memory, because music classes require the constant processing and remembering of audial stimuli [34], while visual working memory 
develops because of the need to read and remember notes [34,35]. Both audio-verbal and visual working memory, together with short-term memory, are essential skills for the remembering of musical pieces.

\subsection{Cognitive Flexibility}

Our study revealed that children taking extra music classes had a higher level of cognitive flexibility, than their peers who took only general music and dance classes. It also coincides with the results of other research works $[18,25]$. However, the majority of papers on this matter do not describe any influence of music classes at preschool age on children's cognitive flexibility and similar parameters, for instance, fluency $[21,22,29,31]$. The study by Shen, Lin, Liu, Fang, \& Liu [25], which also registered the connection of music classes and cognitive flexibility, also used the "Dimensional Change Card Sort" [28] tool, similarly to the current study. The duration of musical intervention was 12 weeks only. "Dimensional Change Card Sort" is not a hard task if compared to other techniques for the diagnostics of cognitive flexibility, and a child with a level of switching ability normal for their age can perform well. While preschoolers can efficiently solve complete switching tasks, more complex ones will remain a challenge for them until a much later age [29]. Perhaps this is why our study did reveal a connection between extra music classes and cognitive flexibility level, when other works did not register any. According to Frischen, Schwarzer, \& Degé, [29], of all three EF components, cognitive flexibility demonstrates the most intensive development at a later age, while senior preschool age is not as sensitive for this component as for the other two. Therefore, in order to develop cognitive flexibility in preschoolers by means of music classes, a much longer course is necessary (over a year). It is noteworthy that in the process of music learning, cognitive flexibility becomes of high demand when a child has already mastered certain skills. While learning the basics, this ability is of less significance. Thus, being able to switch one's attention in the process of playing music is necessary for the transition from one musical instruction to another; for switching from one's section to the section of another performer; and for the creation of musical material during improvisation [29]. All of these skills are normally developed in more advanced students, and cannot be categorized as basic.

\subsection{Interrelation of All EF Components}

By using correlation Pleiades, our work revealed that the children who took regular extra music classes in art schools demonstrated better coordination of the development of different EF components than children from the "general music and dance" group. It allows the conclusion to be drawn that music classes engage all components of EFs. Nevertheless, neither the "extra music" nor the "general music and dance" group demonstrated any correlations with behavioral inhibitory control. This means that his component is the least demanded in the process of basic music learning. Thus, we can say that regular music classes are a favorable activity for EF training, because they actively engage all of the components.

\subsection{Limitations and Further Research}

Since in our study children from the "extra music" group took comprehensive (mixed) music classes, it remains unclear which elements of those classes supported EF development. In other cases, children also received a whole complex of music education that included various activities, and those studies ended with the same open question [29]. Therefore, we could assume that it was the playing of musical instruments that made the decisive difference, or the participation in group musical activity (in a choir or in an orchestra), or the requirement to listen to the rhythm and follow it, etc. Therefore, in the context of future research, it seems promising to study the influence of individual musical disciplines on EF development, and the role of contributing factors. Among the latter, we could name homework volume, the size of the group the child is part of, the relationships in the group in the art school, parents' attitudes towards music classes, and other social and emotional 
factors. An updated version of the questionnaire to be used in the second series of this study, to divide children into "musical" or "non-musical" groups, will include questions about their domestic musical environment (if it is common for the family to listen to music or sing and play musical instruments together), and parents' views on music. There will be also questionnaires for the music school teachers, to discover children's initial faculties for music, and obtain more detailed information on the nature of music classes.

The "extra music training" group also includes children who take extra music classes only, as well as children who also take dancing classes. We allowed such grouping because preschool music training includes elements of dancing and other motor activities (claps, circle dance, etc.). In addition, music and dance training have a lot in common, and both require an understanding of rhythm, mood, tonality, pace, etc. Moreover, Russian preschool education offers general music and dancing classes by default, so it is nearly impossible to find a group of children who would not have any experience of music and/or dance training at all. This explains the grouping logic of our study: "extra music training" as opposed to "general music training". However, it is important to avoid mixed grouping in further studies. Therefore, future experimental groups should include children who do not take extra dance classes, and take music training in the same conditions: the types of music activities, the duration of training, the frequency of classes, etc.

Choosing the right methods of testing EF is important while planning further research. Some tests, such as DCCS, are too easy for 5-6-year-old children, most of whom complete them successfully; therefore, it seems appropriate to introduce more sensitive methods. For preschool children it is also important to choose such methods which offer enough sensitivity to monitor how EFs change over short periods of time [12].

One question still remains open at the end of the current research, and it concerns the children who attend art schools. It is quite possible that such children initially had a higher level of developed of EFs and other specific abilities (such as better a faculty for music, higher intelligence, etc.). Unfortunately, it is impossible to define a causal relationship in this case. Other research works on this matter cannot help either, because they also have correlational designs $[36,37]$. Moreover, a meta-analysis revealed that the better a research design is and the more contributing factors are taken into consideration, the lesser the connection is between music classes and cognitive development [36,37]. In addition, those parents who want music education for their children may be part of a special group in terms of their social status, level of education, attitudes towards music, etc., which would make such a group unrepresentative of all children in the population [13].

Our work was a pilot study, and therefore, has weak spots, which were analyzed and which will be taken into account further on. Thus, further well-designed experimental research is required for the definition of a causal relationship between music classes and EF development.

\section{Conclusions}

We conducted a pilot study which showed that children who take extra music classes in art schools have a higher level of inhibitory control, audio-verbal working memory, cognitive flexibility, and general coordination of all EF components than children who take only general music and dance classes in preschools. We analyzed the limitations of our research, as well as the research works of other authors, which allowed us to come up with a thorough research design of this topic going forward. Further research should include children who do not have any experience of taking extra music and dance classes. The children should be pre-tested for their EF levels before taking the music classes. It is important to randomly assign the children into groups, to separate the effects of the music classes from any previously existing differences between the groups. During the post-test, we recommend offering children new tasks with alternative stimuli, but of approximately the same level of difficulty and task nature compared to the pre-test. It is also crucial to monitor demographic data, including family socioeconomic status, parent education level, and music aptitude. Control groups can be the following: children who do not take 
any extra classes and children who engage in other activities that require the intensive use of EF (e.g., team sports, chess) with the same duration and frequency as in the music group. It would also be valuable to the research to make several experimental groups who take various types of music classes: in groups or individually, and comprehensive music education or learning only one musical instrument. It is also possible to assess the differences between taking short-term (e.g., two times a week for 6 weeks) and longterm music classes (two times a week for 6 months). The development of music courses should be conducted by psychology experts, as well as professional music teachers. Ideally, the teachers should not be aware of the goals of the research to avoid extra influence on EF development.

Author Contributions: Conceptualization, A.V. and L.B.; methodology, A.V.; software, O.A.; validation, O.A. and A.D.; for-mal analysis, O.A.; investigation, E.C.; resources, E.C.; data curation, L.B.; writing-original draft preparation, E.C.; writing-review and editing, E.C.; visualization, O.A.; supervision, A.V.; project administration, A.V.; funding acquisition, A.V. All authors have read and agreed to the published version of the manuscript.

Funding: This study was conducted with the support of the Russian Science Foundation Grant No. 21-78-10153.

Institutional Review Board Statement: The study was conducted in accordance with the Declaration of Helsinki, and approved by the by the Ethical Committee of the Department of Psychology, Lomonosov Moscow State University (approval no: 2021/81).

Informed Consent Statement: Informed consent was obtained from all subjects involved in the study.

Data Availability Statement: The data presented in this study are available on request from the corresponding author.

Conflicts of Interest: The authors declare no conflict of interest. The funders had no role in the design of the study; in the collection, analyses, or interpretation of data; in the writing of the manuscript; or in the decision to publish the results.

\section{References}

1. Garon, N.; Bryson, S.E.; Smith, I.M. Executive function in preschoolers: A review using an integrative framework. Psychol. Bull. 2008, 134, 31-60. [CrossRef]

2. Romine, C.B.; Reynolds, C.R. A model of the development of frontal lobe functioning: Findings from a meta-analysis. Appl. Neuropsychol. 2005, 12, 190-201. [CrossRef] [PubMed]

3. Miyake, A.; Friedman, N.P.; Emerson, M.J.; Witzki, A.H.; Howerter, A. The unity and diversity of executive functions and their contributions to complex "frontal lobe" tasks: A latent variable analysis. Cogn. Psychol. 2000, 41, 49-100. [CrossRef] [PubMed]

4. Best, J.R.; Miller, P.H. A developmental perspective on executive function. Child Dev. 2010, 81, 1641-1660. [CrossRef] [PubMed]

5. Willoughby, M.T.; Kupersmidt, J.B.; Voegler-Lee, M.E. Is preschool executive function causally related to academic achievement? Child Neuropsychol. J. Norm. Abnorm. Dev. Child. Adolesc. 2012, 18, 79-91. [CrossRef]

6. Diamond, A. Executive functions. Annu. Rev. Psychol. 2013, 64, 135-168. [CrossRef]

7. Veraksa, A.N.; Veraksa, N.E. Interconnection of metacognition and executive functions in childhood: Cultural-historical context. Vestn. Mosk. Univ. Seriya 14 Psikhologiya (Mosc. Univ. Psychol. Bull.) 2021, 1, 79-113. [CrossRef]

8. Sabirova, E.G.; Zaripova, Z.F.; Mikhaylovsky, M.N.; Serebrennikova, Y.V.; Torkunova, J.V.; Buslaev, S.I. Recreating Imagination and Self-Regulation as Means of Mathematical Thinking Development in Inclusive Education. Eurasia J. Math. Sci. Technol. Educ. 2020, 16, em1890. [CrossRef]

9. Diamond, A.; Lee, K. Interventions shown to aid executive function development in children 4 to 12 years old. Science 2011, 333, 959-964. [CrossRef]

10. Kholodova, O.L.; Loginova, L.V. Factors of emotional well-being of preschool children: A systematic review. Presch. Educ. Today 2020, 4, 34-49. [CrossRef]

11. Williams, K.E.; Barrett, M.S.; Welch, G.F.; Abad, V.; Broughton, M. Associations between early shared music activities in the home and later child outcomes: Findings from the Longitudinal Study of Australian Children. Early Child. Res. Q. 2015, 31, 113-124. [CrossRef]

12. Bowmer, A.; Mason, K.; Knight, J.; Welch, G. Investigating the Impact of a Musical Intervention on Preschool Children's Executive Function. Front. Psychol. 2018, 9, 2389. [CrossRef]

13. Bugos, J.A.; DeMarie, D. The effects of a short-term music program on preschool children's executive functions. Psychol. Music 2017, 45, 855-867. [CrossRef] 
14. Chen, J.; Scheller, M.; Wu, C.; Hu, B.; Peng, R.; Liu, C.; Liu, S.; Zhu, L.; Chen, J. The relationship between early musical training and executive functions: Validation of effects of the sensitive period. Psychol. Music 2021, 50, 86-99. [CrossRef]

15. Román-Caballero, R.; Vadillo, M.; Trainor, L.; Lupiáñez, J. Please Don't Stop the Music: A Meta-Analysis of the Benefits of Learning to Play an Instrument on Cognitive and Academic Skills. PsyArXiv 2020. [CrossRef]

16. Winsler, A.; Ducenne, L.; Koury, A. Singing one's way to self-regulation: The role of early music and movement curricula and private speech. Early Educ. Dev. 2011, 22, 274-304. [CrossRef]

17. Moreno, S.; Bialystok, E.; Barac, R.; Schellenberg, E.G.; Cepeda, N.J.; Chau, T. Short-term music training enhances verbal intelligence and executive function. Psychol. Sci. 2011, 22, 1425-1433. [CrossRef]

18. Holochwost, S.J.; Propper, C.B.; Wolf, D.P.; Willoughby, M.T.; Fisher, K.R.; Kolacz, J.; Volpe, V.V.; Jaffee, S.R. Music education, academic achievement, and executive functions. Psychol. Aesthet. Creat. Arts 2017, 11, 147-166. [CrossRef]

19. Jaschke, A.C.; Honing, H.; Scherder, E.J.A. Longitudinal Analysis of Music Education on Executive Functions in Primary School Children. Front. Neurosci. 2018, 12, 103. [CrossRef]

20. Frischen, U.; Schwarzer, G.; Degé, F. Comparing the effects of rhythm-based music training and pitch-based music training on executive functions in preschoolers. Front. Integr. Neurosci. 2019, 13, 41. [CrossRef]

21. Hennessy, S.L.; Sachs, M.E.; Ilari, B.S.; Habibi, A. Effects of music training on inhibitory control and associated neural networks in school-aged children: A longitudinal study. Front. Neurosci. 2019, 13, 1080. [CrossRef]

22. Fasano, M.C.; Semeraro, C.; Cassibba, R.; Kringelbach, M.L.; Monacis, L.; de Palo, V.; Vuust, P.; Brattico, E. Short-term orchestral music training modulates hyperactivity and inhibitory control in school-age children: A longitudinal behavioural study. Front. Psychol. 2019, 10, 750. [CrossRef] [PubMed]

23. Bolduc, J.; Gosselin, N.; Chevrette, T.; Peretz, I. The impact of music training on inhibition control, phonological processing, and motor skills in kindergarteners: A randomized control trial. Early Child Dev. Care 2020, 191, 1886-1895. [CrossRef]

24. Roden, I.; Kreutz, G.; Bongard, S. Effects of a school-based instrumental music program on verbal and visual memory in primary school children: A longitudinal study. Front. Psychol. 2012, 3, 572. [CrossRef] [PubMed]

25. Shen, Y.; Lin, Y.; Liu, S.; Fang, L.; Liu, G. Sustained effect of music training on the enhancement of executive function in preschool children. Front. Psychol. 2019, 10, 1910. [CrossRef] [PubMed]

26. Korkman, M.; Kirk, U.; Kemp, S.L. NEPSY II. Administrative Manual; Psychological Corporation: San Antonio, TX, USA, 2007.

27. Korkman, M. Applying Luria's diagnostic principles in the neuropsychological assessment of children. Neuropsychol. Rev. 1999, 9, 89-105. [CrossRef]

28. Zelazo, P.D. The Dimensional Change Card Sort (DCCS): A method of assessing executive function in children. Natl. Protoc. 2006, 1, 297-301. [CrossRef] [PubMed]

29. Frischen, U.; Schwarzer, G.; Degé, F. Music lessons enhance executive functions in 6- to 7-year-old children. Learn. Instr. 2021, 74, 101442. [CrossRef]

30. Alemán, X.; Duryea, S.; Guerra, N.G.; McEwan, P.J.; Muñoz, R.; Stampini, M.; Williamson, A.A. The effects of musical training on child development: A randomized trial of El Sistema in Venezuela. Prev. Sci. 2017, 18, 865-878. [CrossRef]

31. D'Souza, A.A.; Wiseheart, M. Cognitive effects of music and dance training in children. Arch. Sci. Psychol. 2018, 6, 178-192. [CrossRef]

32. Bukhalenkova, D.A.; Gavrilova, M.N.; Airapetyan, Z.V.; Semenov, Y.I.; Tarasova, K.S. Relation between play preferences at home and self-regulation in preschool children. Natl. Psychol. J. 2020, 2, 99-108.

33. Tikhomirova, T.N.; Malykh, A.S.; Malykh, S.B. Visuospatial Working Memory Development across Years of Schooling. Psychol. Russ. State Art 2020, 13, 207-222. [CrossRef]

34. Ho, Y.-C.; Cheung, M.-C.; Chan, A.S. Music training improves verbal but not visual memory: Cross-sectional and Longitudinal explorations in children. Neuropsychology 2003, 17, 439-450. [CrossRef]

35. Boyko, L.A.; Tereshchenko, L.V.; Velichkovsky, B.B.; Latanov, A.V. Visual-motor activity of professional pianists at sight-reading music. Mosc. Univ. Psychol. Bull. 2019, 2, 3-26. [CrossRef]

36. Sala, G.; Gobet, F. Cognitive and academic benefits of music training with children: A multilevel meta-analysis. Mem. Cogn. 2020, 48, 1429-1441. [CrossRef]

37. Sala, G.; Gobet, F. When the music's over. Does music skill transfer to children's and young adolescents' cognitive and academic skills? A Meta-Analysis. Educ. Res. Rev. 2017, 20, 55-67. [CrossRef] 